\title{
From ISBD(CF) to ISBD(ER): Process, Policy, and Provisions
}

\section{Ann Sandberg-Fox and John D. Byrum}

\begin{abstract}
The International Standard Bibliographic Description for Computer Files $(I S B D(C F))$ has been revised recently to take account of rapid changes in this important medium. In addition to setting out the process by which the revision was accomplished and the policies incorporated in the International Standard Bibliographic Description for Electronic Resources (ISBD $(E R)$ ), we provide a detailed indication of the stipulations of the ISBD $(E R)$. With the emergence of this international standard, the next step is for the agencies responsible for national cataloging codes to update their rules.
\end{abstract}

\section{Background: Process for REVISION OF ISBD(CF)}

The first edition of the International Standard Bibliographic Description for Computer Files (ISBD (CF)) was published in 1990, following considerable study of the evolving medium and developmental work to articulate appropriate bibliographic practices. This standard focused on two principal aspects of computer files: software programs and machine-readable databases. ISBD (CF) proved successful in its effort to provide internationally acceptable provisions; the Anglo-American Cataloguing Rules, $2 \mathrm{~d}$ ed., revised (AACR2R), for example, incorporated many of its recommendations and stipulations.

Technology, however, has evolved at a relentlessly rapid pace throughout the 1990s and new forms of computer files have been quick to emerge. By 1994, the International Federation of Library Associations' (IFLA) Sections on Cataloguing and on Information Technology, the groups that had jointly sponsored devel- opment of the ISBD $(\mathrm{CF})$, decided to initiate a revision of the existing standard, despite its relatively recent publication. The ISBD(CF) Review Group was formed to include experts from the $\mathrm{Li}$ brary of Congress (LC), Uppsala Universitetsbibliotek, Bibliothèque National de France, and Biblioteca Nacional (Madrid), with John Byrum as chair and Ann Sandberg-Fox as editor. In addition, eight corresponding members volunteered to participate, with the result that specialists from the United Kingdom, Canada, the Netherlands, Denmark, Finland, and Croatia were also involved.

The review group was charged to examine the ISBD (CF) in all its provisions in order to ensure its ability to meet the current bibliographic needs of users in this highly volatile area. In particular, attention was directed to four developments:

1. The emergence of interactive multimedia, a still developing technology that combines and stores products of

ANN SANDBERG-FOX (afox@smevt.edu) is a cataloging consultant and trainer in Fairfax, Vermont. John D. Byrum (jbyr@seql.loc.gov) is Chief of Regional and Cooperative Cataloging, Library of Congress, Washington, D.C. Manuscript received December 2, 1997; accepted for publication February 10, 1998. 
audio and video technologies, together with text and graphics, on optical discs, needed fuller treatment in the ISBDs. While the computer aspects of this material involve ISBD $(\mathrm{CF})$, the audio and video aspects are covered by the ISBD for nonbook materials (ISBD(NBM)). Because computer technology is essential in using this material, there has been strong support for treating it as a computer file. If ISBD(CF) were to be applied, there would be particular need to define this material in relation to other types of computer files. There would also be the need to review and revise stipulations, particularly in areas 1 (Title), 3 (Edition), and 5 (Physical description), to accommodate interactive multimedia.

2. Developments in optical technology had resulted in new and improved optical discs to replace magnetic disks as primary storage devices. These included more efficient CD-ROMs (compact disc read-only memory) and CD-Is (compact disc-interactive), and the new Kodak photo CDs (photo-optical compact disc). Provisions in area 5 (Physical description) of ISBD $(\mathrm{CF})$ for describing optical discs covered only CD-ROMs, merely described as "compact disks." The term "disk" had been used throughout area 5 to describe both optical and magnetic devices. Further identification was considered necessary in current descriptions to distinguish among the various optical storage devices. Consideration also was needed for the proposed use of the spellings "disc" and "disk" to differentiate between optical and magnetic devices respectively.

3. The rapidly increasing availability of remote electronic files on the Internet needed greater attention than received in the ISBD $(\mathrm{CF})$. The Internet had emerged as a global network that allowed users access to a vast wealth of remote electronic files.
Libraries had started to catalog this online material-particularly electronic journals and other textual files considered of value to their collections. The debut of the OCLC Online Computer Library Center, Inc. Intercat project in 1993 demonstrated interest in providing bibliographic access to these remote resources. Although ISBD(CF) covered remote electronic files, with specific stipulations for their description in area 3 (Type and extent of file), only limited treatment had been given to them because they were a relatively new phenomenon. Designations of the type of file had been limited to general terms only-"Data" and "Program" - and their combination "Data and program." These terms were considered inadequate to identify the many different types of data files and software on the Internet. Also, information on the mode of accessing remote electronic files is provided for in area 7 (Notes) of ISBD(CF), but examples of the access note in this area only gave brief, generalized instructions. In the networked environment of the Internet-in which an electronic file may be accessed by several methods and reside in many directories-more detailed information has been considered necessary for users to be able to locate and retrieve such files.

4. Finally, reproductions of computer files presented a bibliographic concern of growing urgency. Increasing numbers of electronic titles were becoming available in a variety of physical formats. In addition to alternative physical carriers (disk and cassette) and carriers of different sizes (3 1/2inch and 5 1/4-inch disks), a computer file might be available in print format and, in the case of remote electronic files, downloaded and copied to a disk or other device. Cataloging practices have varied on how to treat copies of computer file titles (as well as reproductions involving other forms of library materials, for that matter). In ISBD (CF), stipulations in 
area 5 (Physical description) were limited to situations where a computer file could be available in alternative physical carriers.

With IFLA sponsorship and additional funding from the Research Libraries Group, the review group initiated its work program by meeting at LC in April 1995. In preparation for this session, the editor prepared a series of seven white papers that were distributed electronically to review group members for comment and discussion. In these papers, a broad spectrum of cataloging issues affecting computer files was addressed. These issues had been the subject of study by ALA cataloging groups as well as the focus of considerable debate on several Internet electronic discussion lists, including AUTOCAT, EMEDIA, and INTERCAT. Issues covered in the papers were: (1) interactive multimedia; (2) the general material designation (GMD); (3) sources of information; (4) reproductions; (5) file designations; (6) publication issues; and (7) a compilation of points and queries relating to definitions, dates of publication, and specific material designations.

Based on responses to these papers, the editor then readied a first draft of the revised ISBD $(\mathrm{CF})$, which was distributed to the review group at the April meeting. Decisions taken at this meeting were then incorporated into a draft revised text that was subsequently issued for worldwide review in September 1995.

Over 30 responses were submitted by individuals and representatives of library associations and national libraries during the six-month review period. Most comments were specific and covered both major and minor stipulations throughout the text. These ultimately consisted of about 110 pages of single-spaced text that included extensive statements (both positive and negative) regarding the primary issues raised in the white papers. A number of respondents offered suggestions for changes and, in some cases, proposed rewordings of the text. For each bibliographic area, the editor developed an issue paper to relay the specific comments in brief form to review group members. Ul- timately, all problems were resolved, and the editor produced a revised version of the newly named International Standard Bibliographic Description for Electronic Resources (ISBD(ER)) for review group members, who voted unanimously to approve it.

Subsequently, the ISBD Maintenance Group, which is responsible for ensuring consistency among the ISBDs, studied the text and suggested a few changes to bring it into closer alignment with the general ISBD framework; the text now incorporates these changes. This final version of the ISBD(ER) was unanimously approved by the members of the IFLA standing committees sponsoring the project and in mid-July 1997 the text was submitted to the firm of K. G. Saur for publication in late August.

\section{Policies and Provisions for $\operatorname{ISBD}($ ER)}

Within this framework, the principal changes made in the ISBD $(\mathrm{CF})$ will now be presented. Changes were made in all areas of the text, but in the case of areas 6 (Series) and 8 (Standard number), changes were so minor that they do not need to be discussed here. To facilitate comparison of the stipulations in the ISBD(CF) with those in the ISBD(ER), changes are identified numerically by area and by stipulation within area.

The revision process of the ISBD $(\mathrm{CF})$ involved three major iterations. These are distinguished here as:

- The first draft of the revised $\operatorname{ISBD}(\mathrm{CF})$ (distributed to review group members)

- The draft revised ISBD(CF) or simply draft revised text (distributed for worldwide review) (ISBD(CF) 1995)

- The published ISBD(ER) (1997)

\section{Area 0: Preliminary Notes}

\subsubsection{SCOPE}

The first issue addressed by the review group concerned whether interactive multimedia was within the scope of the 
revised $\mathrm{ISBD}(\mathrm{CF})$. In the white paper on this issue, the editor described developments in the technology and the work of the U.S. cataloging community in preparing the Guidelines for Bibliographic Description of Interactive Multimedia (Guidelines 1994), which had recently been approved by the Association for Library Collections and Technical Services (ALCTS) Committee on Cataloging: Description and Access (CC:DA). Under the Guidelines, interactive multimedia was identified as a unique class of library material to be cataloged with its own GMD. The review group, however, found that such material was within the scope of the ISBD $(C F)$, because it was characterized by its use of computer-controlled technology to access and manipulate its content. As a result, provisions were either added or amended to show inclusion of this material. For the most part, the text of these provisions was derived from specific instructions in the Guidelines (1994).

The scope was also revised to provide more specific direction for treatment of items with a multi-ISBD character (e.g., a computerized map). The general instruction in ISBD $(\mathrm{CF})$ - which directed users to consult the available ISBDs as neededwas considered inadequate; comments received from the review underscored the need for more specific guidance. As a result, the text in ISBD(ER) 0.1.1 now recommends that a bibliographic agency first make full use of the stipulations in the ISBD(ER) and apply provisions of other ISBDs as appropriate. If preferred, however, an agency can apply another ISBD appropriate for the material, supplemented with application of the ISBD(ER).

Finally, new text was introduced in $\operatorname{ISBD}(\mathrm{ER}) 0.1 .1$ to identify edition issues associated with electronic resources and possible methods of treatment. The purpose of this text was to inform users early on about these situations and their treatment, and to reference the specific areas-- 2 (Edition) and 5 (Physical description) - where they are addressed in detail.

\subsection{DEFINITIONS}

The addition of new terms to the list in the ISBD $(C F)$ was predictable, given devel- opments in computer technology and the cataloging of computer files that had occurred since its publication in 1990. The list of 63 terms in the ISBD(CF) was initially expanded to 73 terms in the draft revised text that was submitted for worldwide review. Later, in response to comments received on review, the definitions to be given in ISBD(ER) were expanded to 101 terms including several technical terms, the new GMD, and 27 resource designations related to area 3 (Type and extent of resource). All terms were originally listed in stipulation 0.2 in the draft revised ISBD $(\mathrm{CF})$; however, for ease of use, the entries and definitions for the GMD, the resource designations, and specific material designations were consolidated later into a listing that is part of Appendix $\mathrm{C}$ in ISBD(ER).

\subsubsection{Order of Preference of SOURCES}

Several substantive changes were made in ISBD (CF) stipulation 0.5.1 to resolve difficulties in applying the existing provisions and to accommodate interactive multimedia and the increase of remote access Internet items. Two excellent source documents available to the review group at the time were the Guidelines (1994) and Cataloging Internet Resources (1995). In addition, the review group considered approaches taken by cataloging groups abroad to develop specific guidance in this area.

The resulting text in the ISBD(ER) 0.5 .1 was derived in part from section $\mathrm{D}$ of the Guidelines and provisions to chapter 9 of AACR2R. These amendments included: (1) recognition that there might be circumstances in which access to the internal sources of information would not be possible (e.g., the inability to load a resource); (2) identification of alternative sources of information in situations where the necessary information was lacking in the preferred sources; (3) instruction to favor the source that provides information applicable to the item as a whole and includes a collective title in the case of interactive multimedia; (4) direction to 
take information from a compressed or unreadable remote access item after it has been processed for use; and (5) a caveat that in the case of all sources to prefer the source that provides the fullest or most complete information, when the information varies in degree of fullness.

In addition, the list of internal sources was expanded to accommodate the description of remote access items on the Internet and World Wide Web better. These sources, which are among those listed in Cataloging Internet Resources (1996), include: first display of information, the header to the file including 'Subject:' lines, home page, TEI (Text Encoding Initiative) header, or other identifying information prominently displayed. With the exception of "home page" and "TEI header," this expanded list conforms to the amendment to $A A C R 2 R$ rule $9.0 \mathrm{~B} 1$.

\subsubsection{PRESCRibed SOURCES}

The reworking of the sources of information in ISBD(CF) 0.5.1 resulted in a similar reworking of the list of prescribed sources in section 0.5 .2 . In place of the verbal explanation given in the $\operatorname{ISBD}(\mathrm{CF})$, the editor decided to use a chart to clarify the prescribed sources in each area. In ISBD(ER) 0.5.2, the specification of sources for use in areas $1,2,4$, and 6 are, in sequence: internal sources; labels on the physical carrier; and documentation, containers, or other accompanying material. In the case of areas $3,5,7$, and 8 , it is permissible to use any source.

\section{Area 1: Title and Statement of RESPONSIBILITY}

With the exception of the GMD, changes in the stipulations in ISBD (CF) area 1 were minor, limited mostly to the addition of a few examples illustrating remote access items; these examples replaced existing examples that were seen as being dated or no longer relevant.

\subsection{General Material Designation}

Undoubtedly, the most notable, albeit controversial, change in area 1 was replac- ing the GMD "computer file" with "electronic resource." This, in turn, resulted in changing the title of the revised document from ISBD (CF) to ISBD(ER) and the replacement of every occurrence of "computer file" with "electronic resource" in the text. The decision to make this change was taken only after extensive review. Although review group members had expressed dissatisfaction with the term "computer file" and seriously considered other possibilities early on in their discussions, they retained it for the GMD because it was judged to be an overall better indicator of the medium than the alternatives considered. In the chair's note accompanying the draft text of the ISBD(ER), this decision was mentioned. Surprisingly, a large percentage of ISBD recipients (approximately 40\%) reacted to this observation, with the majority indicating varying degrees of dissatisfaction with "computer file" and, in a few cases, proposing possible replacement terms. Independent of these responses, subscribers to INTERCAT participated in a lively debate concerning this topic in which they questioned the relevance of the term "computer file" to represent material on the Internet and on CD-ROMs (GMD 1995).

There was a decided need to revisit the issue. Possible terms that the review group considered earlier included "resource," "file," "document," and "record," modified by the terms "electronic" and "digital." Of these, the term "electronic resource" received the greatest support. Translation of the term into other languages was not deemed to be problematic by the European members of the review group. They pointed out the existing lack of one-to-one equivalency in translating "computer file" into their languages, resulting in the substitution of other terms. For example, in France, the equivalent of the term "electronic" (électronique) had already been used for translation of "computer" in the original GMD. Finally, what perhaps best describes the rationale for the choice of "electronic resource" as the new GMD is expressed by Beaney (1996), who wrote: "We like the term ['electronic resource'] because it is 
general, easily understood outside cataloguing circles, and is relevant to collections of both remote and local files."

\section{Area 2: Edition}

\subsection{EDITION STATEMENT}

Several substantive changes were made in area 2 of the ISBD(CF). These concerned section 2.1, which involved clarifying the concept of "edition" and reconsidering the issue of single and separate records, particularly as related to remote access items. In the text of $\operatorname{ISBD}(\mathrm{ER}) 2.1$, the occurrence of a new edition continues to be linked to changes in the intellectual or artistic content of the item that would result in the creation of a separate bibliographic record. However, items in different system-related formats (e.g., IBM and Macintosh), which were treated as distinct editions in the ISBD $(\mathrm{CF})$, are not considered sufficiently different to constitute a new edition or to warrant a separate bibliographic record in the $\operatorname{ISBD}(E R)$. Additionally, items in different types of physical carriers and items in different output media or display formats were also not considered distinctive editions in the ISBD(ER).

A new paragraph was also added in ISBD (ER) 2.1 to provide treatment for items with multiple edition statements, specifically interactive multimedia; in this text, which was derived from the Guidelines (1994, section I), the cataloger is instructed to transcribe the statement that relates to the item as a whole; if there is no one statement that applies to the item, then that or any additional statements may be given in area 7.

Two remaining concerns with section 2.1 resulting from the review of the revised text were the treatment of frequently updated resources and use of the term "version" as being synonymous with "edition."

The first concern centered on the description of remote access items, which are subject to frequent or continuous updating. Some of the ISBD respondents noted that the highly changeable nature of these remote access materials made upkeep of existing records and the creation of new records extremely troublesome. In an attempt to help stabilize the bibliographic description for such items, an instruction was added in ISBD(ER) 2.1 to omit edition statements altogether in the edition area and, instead, to give an appropriate note:

Frequently updated; Last update: $2 / 18 / 97$. Continuously updated; Version 7 dated: May 5, 1997.

The second concern was whether the term "version" should be considered synonymous with "edition." In ISBD(CF), the terms "version," "level," "release," and "update" were equated with "edition," which implied justification for the creation of new descriptions. In comments on the draft revised text, it was noted that "version" served sometimes as an indicator of major changes and at other times as an indicator of minor changes. It was thus clear that the terms, although related, should not be treated as synonymous. The resulting text in ISBD(ER) 2.1 reflects this ambiguity by stating that "version" and other related terms can indicate an edition statement; however, because they might indicate either major or minor changes, they are not necessarily a reliable guide to indicate a new edition.

\section{AREA 3: TyPe AND EXTENT OF ITEM}

Of all the areas in the $\operatorname{ISBD}(\mathrm{CF})$, area 3 received the most extensive revision. In basic orientation, the text of ISBD(ER) area 3 remains the same as in the $\operatorname{ISBD}(\mathrm{CF})$, that is: designation of the type of item is mandatory in the description of remote access items and optional for local or direct access items, with extent or size of item to be given when the information is available and the bibliographic agency wishes to record it. In all other respects, however, this area was thoroughly reworked to improve its usefulness in identifying the variety of remote access items now available on the Internet and World Wide Web. 


\subsection{DeSignation OF Item}

The revision centered on ISBD $(\mathrm{CF})$ section 3.1 and the associated list of file designations that now appear in Appendix C. At the time of the ISBD(CF) revision project, the three designations allowed-"Data," "Program(s)," and "Data and program(s)"-were seen to be too limited to provide a meaningful or useful identification of many of the items that had become widely available online. Two failed attempts to expand these particular designations were reviewed. One such attempt was a proposed list of 17 additional terms presented in the Guidelines (1993, B:5). A CC:DA task force charged with reviewing the manual disapproved of the expansion and open-ended provision to add more terms as needed, but decided to make its own attempt to expand the list by proposing a compromise to add specific modifying terms in parentheses following the existing designations (e.g., "Computer data (Numeric)"). While this approach built on the present designations and their structure, it did not address the problem of additional information appropriate to this data element (number of files, records, statements, and bytes) which when included made the designation unwieldy. In its final report to CC:DA, the task force withdrew its proposed compromise (ALCTS CC:DA Task Force1993).

In the white paper distributed to the review group on this issue, the editor offered another approach for consideration that borrowed from these attempts. This solution was to retain the present designations and modify them, if desired, with the list of terms given in the fixed field $008 / 26$ (type of computer file) in the $1988^{\circ}$ edition of the USMARC Format. For "data" these terms were "Numeric" (code a), "Representational" (code c), and "Text" (code d), with the resulting designations:

Computer numeric data

Computer representational data

Computer text data

In the case of "Computer program" (code b), the editor suggested the modifi- ers "application" and "system" be used as appropriate:

Computer application program

Computer system program

The review group endorsed this approach, but decided that these terms should be further expanded to accommodate other types of files. An additional list of 22 designations that could be used singly or in various combinations was proposed. These designations consisted of well-established terms widely used in the global computing community of producers and users. A particular effort was made to ensure that all chosen terms be mutually exclusive.

Three levels of specificity were introduced, starting with the present three generic designations at the first or top level. Specific designations representing these categories were listed at the second or middle level, and, in turn, more specific designations for these categories were listed at the third level:

\section{First level: Computer data}

Second level: Computer numeric data

Third level: Computer census data

Designations at any one of these levels could be used as desired by the bibliographic agency. In the case of data and program combinations, specific designations could be combined:

Computer census data and spreadsheet program

In the case of "interactive multimedia" and "online service(s)," these terms may be used singly or in combination with other terms:

Computer interactive multimedia

Computer interactive multimedia game

Following extensive discussion, the final list of 30 designations was approved and incorporated into Appendix $\mathrm{C}$ of the draft revised ISBD $(C F)$ that was sent for review.

Overall, comments from ISBD recipients were supportive of the proposed des- 
ignations. Suggestions were made to clarify some designations and to request definitions for all designations. A concern was expressed that the list appeared to be closed, a condition that might limit its future usefulness. Also, with the flexibility allowed in choosing levels of designations, some commentators wondered about lack of uniformity in bibliographic descriptions.

However, what was unexpected were several comments concerning the description of physical details (sound, color) and accompanying material relating to remote access items. Direction in the "Introductory note" to area 3 in the $\operatorname{ISBD}(\mathrm{CF})$ called for giving this information in area 7; this direction had been retained in the draft of $\operatorname{ISBD}(\mathrm{CF})$ that was circulated for review. Responses from about $25 \%$ of the reviewers ranged from calling for the abolition of area 3 in favor of giving the information in areas 5 or 7 , to suggesting that the sections in areas 3 and 5 be harmonized, to requesting that all sections in area 3 be made optional.

To resolve this issue, review group members were surveyed to select from among the following alternatives: (1) to retain the provision in the draft revised $\operatorname{ISBD}(\mathrm{CF})$ text, which allowed for the physical details for remote access items to be given in area $7 ;(2)$ to give the physical details in area 3 on an optional basis, following the file designation; or (3) to record the physical details in area 5 on an optional basis in addition to giving the file designations in area 3 as listed in Appendix C. Responses from members indicated a majority preference for the first of these options.

Following the decision to change the GMD to "electronic resource," the designations in Appendix C, in turn, were introduced with the word "electronic" in place of "computer." A separate list of these designations without the word "electronic" was also included in the ISBD(ER) to accommodate bibliographic agencies giving the GMD in their bibliographic descriptions.

In response to the concern about the list of designations being closed, a provision was added to authorize the user to supply an appropriate designation when none of the designations in Appendix C was appropriate. As to the choice of a term, catalogers are instructed to prefer a term that is currently well established, in use by both the producers and users of the particular resource, and is mutually exclusive of other terms used as designations. Finally, as noted earlier, definitions for the designations listed in Appendix $\mathrm{C}$ were added to Appendix $C$ in the $\operatorname{ISBD}(\mathrm{ER})$.

\subsection{Extent of File}

Two remaining changes concerned ISBD $(\mathrm{CF})$ section 3.2. The first involved inserting text in the introductory paragraph regarding compressed forms of remote access items. In ISBD(ER) 3.2, the text reads (1997, 53): "When the resource is in a compressed form, the bibliographic agency may omit this information."

The second change resulted in revising the punctuation pattern from introducing information on "extent" with a colon space after the number of files to a space, colon, space, which conforms to the punctuation pattern given for recording this information in chapter 9 of AACR2R (1988, rule 9.3B2):

ISBD(CF); Computer data (1 file: 96007 bytes)

ISBD(ER): Computer data (1 file : 96007 bytes)

\section{Area 4: Publication, Distribution, ETC.}

The major concern with ISBD(CF) area 4 was whether the stipulations were adequate for the treatment of remote access items. Concerns were centered, in particular, on the stipulations regarding publication and dates. With respect to publication, examination of the provisions throughout this area showed uniform treatment for cataloging all computer files - both remote access and local or direct access-as being published. The consequence was that formal statements of publication that included place, publish$\mathrm{er}$, and date were given in area 4 when the 
information was available; otherwise, if such information were lacking, the abbreviations "s.l." and "s.n." were given.

In contrast to this treatment, chapter 9 in AACR2R calls for the cataloger to distinguish between published and unpublished items, and to apply differing cataloging treatments for each category. In the case of unpublished items, only date information would be given (AACR2R 1988 , rules $9.4 \mathrm{~F} 1,9.4 \mathrm{~F} 2$ ). These instruc tions became the topic of considerable discussion in the cataloging community when libraries started to catalog material on the Internet as part of the INTERCAT project. The question of whether remote access material should be considered published was addressed in a set of guidelines published in Dillon and others (1993, B:2) with the suggestion that a remote access item be treated as published if it carries a formal statement of publication, or as unpublished if it lacked such a statement. In the later revised text (Cataloging Internet Resources 1995), this suggestion was amended to treat all items on the Internet selected to be cataloged as published items. In essence, this treatment conformed to that found in the ISBD (CF).

In an attempt to apprise review group members of the discussion and varying treatment for describing remote access items, the editor prepared a paper on the topic. Responses indicated that members found the ISBD $(\mathrm{CF})$ sections to be adequate, with some recommending that the treatment of remote access items be clearly stated in the "Introductory note" to the area. In addition, the position that all remote access resources are considered to be published is given in a footnote in stipulation 0.1.1 (Scope) and is mentioned in the definition for "publication" of remote access items in stipulation 0.2.

\subsection{Date of Publication, PRODUCTION, OR Distribution}

With respect to dates, the difficulty was in providing treatment for online services and other dynamic resources, such as World Wide Web sites, whose publication dates frequently change in conjunction with changes in their content. Such dates commonly appear in these items in the form of month, day, and year, followed at times with a precise recording of the time in hours, minutes, and seconds. Giving an open date in the cataloging record for these items, as in the case of multipart items, was considered, but was found to be insufficient to reflect this situation. After worldwide review, however, this issue was revisited. Subsequently, text was added in ISBD(ER) stipulation 4.4.1 to allow for a note to indicate the month, day, and year that appear in a dynamic resource, e.g.:

Description based on version dated: Oct. 4, 1997 13:22:11.

Description based on home page dated: 09/06/96.

The related note for indicating the frequently changing content of these resources, discussed in section 2.1, could also be used in conjunction with this note.

Another concern regarding dates was the treatment of items, such as interactive multimedia, that contained multiple copyright dates associated with their production (e.g., written program, sound production, graphics). It was decided that a new stipulation should be added to address this situation. The text of ISBD $(E R)$ stipulation 4.4.7.1 was derived from the Guidelines (1994, section J) and contains instructions that the latest copyright date should be given when there is no other date in the item applicable to the item as a whole. It does not matter whether the copyright date appears in conjunction with the written program or some other aspect of the production.

\section{Area 5: Physical Description}

ISBD (CF) area 5 was the focus of considerable revision, which resulted in several substantive changes. First, the "Introductory note" was completely reworked to address edition issues associated with physical carriers available in different types and sizes, in different system- and printer-related formats, and in different output or display formats. In all these situations, the ISBD $(\mathrm{ER})$, which builds on 
the basic text in the ISBD (CF), offers the choice of making separate bibliographic descriptions for each physical carrier involved or, alternatively, making distinct physical descriptions for each carrier in the same bibliographic record. In the latter approach, each description would occupy a separate line in the record or could be grouped in a single continuous line. In addition, a new paragraph was added to cover the treatment of interactive multimedia made up of two or more physical carriers, with distinct physical descriptions mandated for each carrier in the same bibliographic record. This treatment is in accord with the preferred treatment in the Guidelines (1994).

\subsection{Specific Material Designation}

The second major change made in ISBD (CF) stipulation 5.1 was the introduction of the spelling "disc" to describe optical physical carriers with the confinement of "disk" to the description of magnetic carriers. This decision was influenced by the adoption of these spellings in the Guidelines (1994, section K), as well as by the results of a survey compiled by Jizba (1996).

\subsubsection{DIMENSIONS}

ISBD(CF) stipulation 5.3.1 was changed to provide an option to express the dimensions of physical carriers in inches rather than in centimeters, as is customary in the ISBDs. This option, which is given in a footnote in the ISBD(ER), was recommended, in particular, by European members of the review group who felt it important that bibliographic agencies be allowed to exercise a choice in this matter.

Review of other stipulations in ISBD $(C F)$ area 5 resulted in the deletion of stipulation 5.1.3 whose provisions for recording the make and model of machine in parentheses after the specific material designation were considered to be outdated. For the same reasons, stipulation 5.2.4, which provided the option of re cording format characteristics that were largely associated with disks, was also deleted. Stipulation 5.3.4 was amended to take into account the description of items consisting of physical carriers of different dimensions. The instruction in the ISBD $(\mathrm{CF})$ to omit such dimensions from the physical description area and to give them optionally in a note was rewritten to incorporate the instruction in $A A C R 2 R$ rule 9.5D2. As a result, ISBD $(E R)$ calls for giving such dimensions in the physical description area, with the smaller or smallest and the larger or largest dimensions separated by a hyphen.

Suggestions stemming from the review of area 5 proposed further clarification of the methods of description set out in the "Introductory note," which was accomplished in the final text of the ISBD (ER). In addition, commentators asked the review group to consider replacing the specific material designation "computer optical disc" with the identification of particular optical disc formats (e.g., CD-I, CD-ROM). After considerable deliberation, a compromise solution was approved in which the designation, "electronic optical disc" would be retained, but an option to name in parentheses one of the following particular disc formats: CD-I, CD-ROM, or Photo CD would be added, e.g., 1 electronic optical disc (CD-ROM). In addition, provision was made to record other optical disc formats as they became known, dependent on the wishes of the bibliographic agency and the established identity of the format by both producers and users of the item. These provisions were incorporated as a new stipulation (5.1.3) in the ISBD(ER).

Finally, review of the treatment for accompanying material in stipulation 5.4 in the draft revised text indicated some confusion in describing these items. The text was subsequently clarified and incorporated in ISBD(ER) stipulation 5.4.

\section{Area 7: Notes}

A lengthy review of ISBD $(C F)$ area 7 resulted in numerous changes throughout the text that were incorporated in the draft revised ISBD(CF). Most noticeable were: (1) the addition of new examples to illustrate interactive multimedia and remote access items that affected the ma- 
jority of the stipulations; (2) the addition of a newstipulation 7.2.2, which separates notes for the bibliographic history of an item from notes for the source of the editionstatement(renumbered7.2.1) and the requirements to give the note for the latterif applicable; (3) the note for system requirements for local or direct access items; and (4) the note for mode of access for all remote access items.

Comments received from the worldwide review prompted further revision. A strong suggestion was made to place the notes for system requirements (7.5.1) and mode of access (7.14, the last listed note) as the first notes, which reflected the directions given in the text of these stipulations. The ISBD schema for this area, however, prevented this reordering. It was then decided to reorder the note for mode of access to its more logical placement following the note for system requirements. In the $\operatorname{ISBD}(\mathrm{ER})$, the former note is listed as 7.5.2; also, additional text was inserted in the "Contents" section introducing this area, to alert bibliographic agencies as to the precedence and mandatory status of these notes.

Other comments from reviewers resulted in expanding the new stipulation 7.2.2 for notes on the bibliographic his tory of an item and stipulation 7.9 for notes on the description of the copy in hand to include, respectively, indications of the frequently changing contents of remote access items and information on the edition or issue used in the description. These notes, discussed earlier in the context of area 2, were incorporated in sequence in the $\operatorname{ISBD}(\mathrm{ER})$.

\section{APPENDIX A: MULTILEVEL DESCRIPTION}

ISBD(CF) Appendix A illustrated the multilevel description of a local access item. This single application was expanded in the draft revised text of the ISBD (CF) to illustrate two choices of multilevel descriptions that pertained both to local and remote access items. Following the review, it was decided to replace one example with a more illustrative title and to add a third choice of multilevel description to further illustrate its application in the ISBD(ER).

\section{APPENDIX B: BIDIRECTIONAL. RECORDS}

There was no example of a bidirectional bibliographic record in ISBD $(\mathrm{CF})$ Appendix $B$ that illustrated scripts written in opposite directions. To remedy this deficiency, an example was found that illustrates an item in both English and Arabic scripts.

\section{APPENDIX D: RECOMMENDED AbBreviations}

The list of three recommended abbreviations in Appendix D of the ISBD (CF) was shortened to two in the draft revised text. Following review, abbreviations for the three optical disc formats, (i.e. CD-I, CDROM, Photo $C D$ ) were added to the ISBD(ER) along with three abbreviations used to express the dimensions of physical carriers in area 5.

\section{APPENDIX E: EXAMPLES}

The ten examples in the ISBD(CF) Appendix $E$ were replaced initially with nine new examples in the draft revised text. Five additional examples were contributed as a result of the review. Consequently, Appendix E of the ISBD(ER) includes 14 examples from the United States, the United Kingdom, Canada, Finland, France, Russia, Slovenia, Spain, and Sweden. These cover a variety of electronic resources including local and remote access items as well as interactive multimedia.

\section{INDEX}

The ISBD $(C F)$ index was not revised until final editing of the ISBD(ER). Major revision was undertaken with the purpose of providing greater in-depth access to the stipulations and their contents. This resulted in the expansion of entries from 107 in the $\operatorname{ISBD}(\mathrm{CF})$ to 272 in the 
TABLE 1

ISBD(ER) Stipulation Changes and AaCR2R Rules AfFected

\begin{tabular}{ccc}
\hline ISBD(ER) Stipulation & Provision/Content & AACR2R Rule \\
\hline 0.1 .1 & Scope & $9.0 \mathrm{~A} 1$ \\
0.5 .1 & Order of Prescribed Sources & $9.0 \mathrm{~B} 1$ \\
0.5 .2 & Prescribed Sources of Information & $9.0 \mathrm{~B} 2$ \\
1.2 & General Material Designation & $1.1 \mathrm{C}$ \\
2.1 & Edition Statement & $9.2 \mathrm{~B} 1$ \\
3.1 & Resource Designations & $9.3 \mathrm{~B} 1$ \\
3.2 & Extent of File & $9.3 \mathrm{~B} 2$ \\
4.4 & Date of Publication & $9.4 \mathrm{~F}$ \\
5.1 & Specific Material Designations & $9.5 \mathrm{~B} 1$ \\
5.2 & Format Characteristics & $9.5 \mathrm{C} 2$ \\
5.3 .1 & Dimensions & $9.5 \mathrm{D} 1$ \\
7.2 .2 & Bibliographic History Note & $9.7 \mathrm{~B} 7$ \\
7.5 .1 & System Requirements Note & $9.7 \mathrm{Blb}$ \\
7.5 .2 & Mode of Access Note & $9.7 \mathrm{Blc}$ \\
7.9 & Resource Described Note & $9.7 \mathrm{~B} 20$ \\
\hline
\end{tabular}

$\operatorname{ISBD}(\mathrm{ER})$, for an increase of approximately $150 \%$.

\section{CONCLUSION}

The focus of this discussion on the principal changes that were made in the ISBD $(\mathrm{CF})$ necessarily overlooks the many other changes of lesser importance that also went into this revision. These ranged from spelling and punctuation oversights to the replacement of outdated examples and the addition of new ones to illustrate pertinent text. Much of this work was aided by written comments submitted by reviewers of the first edition, and later by reviewers of the two early iterations of the ISBD(ER).

\section{IMPLICATIONS FOR AACR2R}

What, may one ask, are the implications of the ISBD(ER) with respect to the development of national cataloging codes and the automated environment in which most cataloging is being done, particularly in the United States? Already activities have been initiated in some European countries to update existing manuals, rules, and codes to incorporate the features of the ISBD(ER). Within ALCTS, CC:DA has taken action to initiate an investigation of the implications of ISBD(ER) for AACR2R chapter 9 (Kin- ney 1997). Table 1 is intended to highlight the most significant provisions of chapter 9 that should be harmonized with $\operatorname{ISBD}(E R)$ as the result of the CC:DA effort.

We recommend that the work needed to update AACR2R chapter 9 be pursued in the near term in order to capitalize quickly on the advances that have been realized with the publication of $\operatorname{ISBD}(\mathrm{ER})$.

\section{WoRKS CITED}

Anglo-American cataloguing rules. 1988. Prepared under the direction of the Joint Steering Committee for Revision of AACR, a committee of the American Library Association, the Australian Committee on Cataloguing, the British Library, the Canadian Committee on Cataloguing, the Library Association, the Library of Congress, $2 \mathrm{~d}$ ed., 1988 revision, ed. Michael Gorman and Paul W. Winkler. Chicago: American Library Association.

Association for Library Collections \& Technical Services. Committee on Cataloging: Description and Access. Task Force on Cataloging Internet Resources. 1993. Final report.

Association for Library Collections \& Technical Services. Committee on Cataloging: Description and Access. Interactive Multimedia Guidelines Review Task Force. 1994. Guidelines for bibliographic description of interactive multimedia. Ed Laurel Jizba. Chicago: American Library Association. 
Beaney, Sandy 1996. E-mail correspondence to Ann Sandberg-Fox. July 22.

Cataloging Internet resources. 1995. Ed. Nancy B. Olson Dublin, Ohio: OCLC Online Computer Library Center.

Cataloging Internet resources. 1996. Ed Nancy B. Olson. Dublin, Ohio: OCLC Online Computer Library Center.

Dillon, Martin, and others. 1993. Assessing information on the Internet. Dublin, Ohio: OCLC Office of Research.

GMD discussion. 1995. INTERCAT August 30-31, September 1, 11-12.

$I S B D(C F)$ : International standard bibliographic description for computer files. 1990. London: IFLA Universal Bibliographic Control and International MARC programme.
ISBD $(C F)$ : International standard bibliographic description for computer files. 1995. $2 \mathrm{~d}$ ed draft. London: IFLA Universal Bibliographic Control and International MARC Programme.

ISBD $(E R)$ : International standard bibliographic description for electronic resources. 1997. Munich: K. G. Saur.

ISBD $(N B M)$ : International standard bibliographic description for non-book materials. 1987. Rev, ed London: IFLA Universal Bibliographic Control and International MARC Programme.

Jizba, Laurel 1996. Survey: Disc/disk and background info. AUTOCAT. August 5-14.

Kinney, Daniel. 1997. E-mail correspondence to John Byrum. November 3.

\section{Elegant Solutions for Preservation}

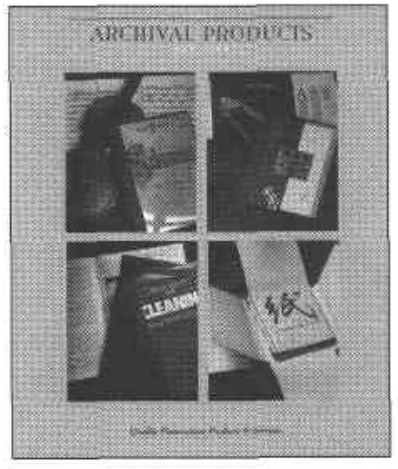

Call for

a complete catalog

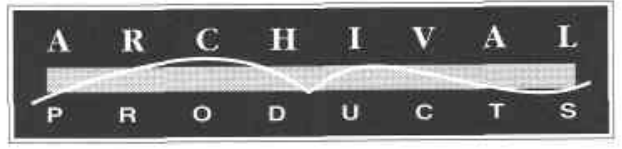

Protective Enclosures

Pamphlet Binders

Music Binders

Bound Four Flap Enclosures

Tan Archival Board

Grey/White Archival Board

Drop Spine Archival Boxes

Academy Folder

Manuscript Folder

3" Ring Binder Album

P.O. Box 1413, Des Moines, Iowa 50305-1413

PH. 800-526-5640

FAX 800-262-4091

E-MAI archival@ix.netcom.com

WEB STIE http://www.archival.com 